\title{
Selective Evolution of Ligands by Exponential Enrichment to Identify RNA Aptamers against Shiga Toxins
}

\author{
Sreerupa Challa, ${ }^{1,2}$ Saul Tzipori, ${ }^{1}$ and Abhineet Sheoran ${ }^{1}$ \\ ${ }^{1}$ Department of Infectious Disease and Global Health, Tufts Cummings School of Veterinary Medicine, Tufts University, \\ 200 Westboro Road, Building 20, North Grafton, MA 01536, USA \\ ${ }^{2}$ AstraZeneca, 35 Gatehouse Drive, Waltham, MA 02451, USA \\ Correspondence should be addressed to Abhineet Sheoran; abhineet.sheoran@tufts.edu
}

Received 19 December 2013; Revised 6 March 2014; Accepted 25 March 2014; Published 15 April 2014

Academic Editor: Birte Vester

Copyright (C) 2014 Sreerupa Challa et al. This is an open access article distributed under the Creative Commons Attribution License, which permits unrestricted use, distribution, and reproduction in any medium, provided the original work is properly cited.

\begin{abstract}
Infection with Shiga toxin- (Stx-) producing E. coli causes life threatening hemolytic uremic syndrome (HUS), a leading cause of acute renal failure in children. Of the two antigenically distinct toxins, Stx1 and Stx2, Stx2 is more firmly linked with the development of HUS. In the present study, selective evolution of ligands by exponential enrichment (SELEX) was used in an attempt to identify RNA aptamers against Stxl and Stx2. After 5 rounds of selection, significant enrichment of aptamer pool was obtained against Stx2, but not against Stxl, using a RNA aptamer library containing 56 random nucleotides (N56). Characterization of individual aptamer sequences revealed that six unique RNA aptamers $(\mathrm{mA} / \mathrm{pC}, \mathrm{mB} / \mathrm{pA}, \mathrm{mC}, \mathrm{mD}, \mathrm{pB}$, and $\mathrm{pD})$ recognized Stx2 in a filter binding assay. None of these aptamers bound Stxl. Aptamers $\mathrm{mA} / \mathrm{pC}, \mathrm{mB} / \mathrm{pA}, \mathrm{mC}$, and $\mathrm{mD}$, but not $\mathrm{pB}$ and $\mathrm{pD}$, partially blocked binding of Alexa 488-labeled Stx2 with HeLa cells in a flow cytometry assay. However, none of the aptamers neutralized Stx2-mediated cytotoxicity and death of HeLa cells.
\end{abstract}

\section{Introduction}

Infection with Shiga toxin- (Stx-) producing Escherichia coli (STEC) is the most significant cause of hemolytic uremic syndrome (HUS), the leading cause of acute renal failure in children [1-4]. Of the two antigenically distinct toxins, Stx1 and Stx2, Stx2 is more firmly linked with the development of HUS as STEC strains producing this toxin are more frequently associated with HUS than strains that produce both Stx1 and Stx2, while Stxl alone has rarely been associated with HUS [5-7]. Stx1 and Stx2 are similar in basic structure [8], binding specificity [8], and mode of action. Both toxins consist of an A-subunit monomer and a B-subunit pentamer [810]. The pentameric $B$ subunit binds to its cell surface receptor CD77, also called globotriaosylceramide (Gb3; Gal $\alpha 1-4 \mathrm{Gal} \beta 1$ 4glucosyl ceramide) [11, 12]. This triggers endocytosis of the holotoxin, mainly through clathrin-coated pits [13]. The internalization of catalytically active A-subunit, delivered to cytosol via retrograde transport, causes shut down of protein synthesis and leads to cell death $[14,15]$.
Nucleic acid aptamers are being developed as therapeutic and diagnostic reagents against biotoxins [16]. Aptamers are short, synthetic, single stranded nucleic acids with unique three-dimensional conformations that bind strongly and selectively to a target molecule via shape specific recognition [17-20]. Aptamers are similar in many respects to antibodies except that they are cheaper to produce, have extremely long shelf lives, and thus, are far more cost effective than to produce antibodies. A single aptamer against a Shiga toxin has been reported, but it is unknown whether the aptamer is against Stx1 or Stx2 [21]. Toxin-neutralizing ability of this toxin is also unknown [21]. The aim of the present study was to utilize selective evolution of ligands by exponential enrichment to identify ribonucleic acid (RNA) aptamers against Stxl and Stx2.

\section{Materials and Methods}

2.1. Stx1 and Stx2. Stx1 and Stx2, purified as described previously [22], were obtained from Phoenix Laboratory (Tufts 
University, NEMC Microbial Products \& Services Facility). Before use, the toxins were passed through Polyacrylamide 6000 Desalting column (Thermoscientific, IL) to suspend them in selection buffer (20 mM HEPES (pH 7.3), $150 \mathrm{mM}$ $\mathrm{NaCl}$, and $5 \mathrm{mM} \mathrm{MgCl} 2$ ). The toxins were quantified by UV spectrophotometry (ND-1000 Spectrophotometer, Nanodrop), aliquoted, and stored at $-20^{\circ} \mathrm{C}$.

2.2. Preparation of RNA Library. The starting ssDNA library containing 56 random nucleotides flanked by constant regions ( $5^{\prime}$-CACAGCGGGACAGTTTAGC - N56 - GGTAGGTGGGTGCGTCTAAA-3') was synthesized by Integrated DNA Technologies, Inc. (Coralville, IA). The DNA random library ( 4 nmoles or approximately $2.4 \times 10^{15}$ sequences in $50 \mathrm{~mL}$, that is, $80 \mathrm{nM}$ ) sequences were amplified by PCR with $200 \mu \mathrm{M}$ of each dNTP along with $2 \mu \mathrm{M}$ each of forward (5'-GATAATACGACTCACTATAGGGCACAGCGGGACAGTTTAGC- $\left.3^{\prime}\right)$ and reverse $\left(5^{\prime}\right.$-TTTAGACGCACCCACCTACC- $3^{\prime}$ ) primers using Taq DNA polymerase (New England Biolabs); the forward primer included a T7 promoter region (underlined) for in vitro transcription. In order to prevent the abundance of the original DNA library, PCR was performed for a total volume of $50 \mathrm{~mL}$ $(100 \mu \mathrm{L} /$ tube $)$ and was limited to 10 cycles. After the PCR reactions, the amplified dsDNA library was subjected to ethanol precipitation and later converted to RNA library using AmpliScribe T7-Flash Transcription Kit (Epicentre, Madison, WI) according to the manufacturer's instructions. The in vitro transcription reaction was set up with $12 \mu \mathrm{L}$ of $65 \mu \mathrm{M}$ of dsDNA (i.e., 0.8 nmoles or approximately $5 \times 10^{14}$ sequences). The RNA was purified after completion of the transcription reaction and resuspended in $200 \mu \mathrm{L}$ of $\mathrm{dH}_{2} \mathrm{O}$. The final concentration of purified RNA was found to be 32 nmoles that would have corresponded to 40 copies of original DNA pool, that is, $5 \times 10^{14}$ sequences ( 0.8 nmoles).

As unmodified RNA molecules are highly susceptible to nuclease degradation, nuclease resistant modifications were introduced chemically to generate modified RNA aptamer library. Modified library was generated by incorporating $2^{\prime}$ Fluorine-CTP (2' -F-dCTP), $2^{\prime}$-Fluorine-UTP (2'-F-dUTP), ATP, and GTP into full length transcripts with in vitro transcription using DuraScribe T7 transcription kit (Epicentre, Madison, WI, USA) as described elsewhere using Y639F mutant of T7 RNA polymerase [23, 24].

\subsection{In Vitro Selection of Aptamers Using Nitrocellulose} Membrane. Systematic evolution of ligands by exponential enrichment (SELEX) using nitrocellulose membrane (mSELEX) was performed as described elsewhere [17] to select aptamers against Stx1 and Stx2. In every round, prior to selection, RNA was thermally equilibrated and refolded in selection buffer by heating to $70^{\circ} \mathrm{C}$ for $3 \mathrm{~min}$ and then slowly cooling to $37^{\circ} \mathrm{C}$ for at least 10 minutes. In order to minimize nonspecific binding of RNA with the nitrocellulose membrane, the refolded RNA pool was preadsorbed to a $0.45 \mu \mathrm{m}$ nitrocellulose HAWP filter (Millipore, Bedford, MA) for $30 \mathrm{~min}$ prior to every round of selection with Stx1 or Stx2.
In the first selection cycle, the precleared random RNA pool (55.2 $\mu \mathrm{g}, 1.6$ nmole, $9.6 \times 10^{14}$ molecules) and Stx1 or Stx2 $(0.4$ nmole, RNA/toxin ratio 4/1) were incubated in $200 \mu \mathrm{L}$ selection buffer on a rotating platform for $30 \mathrm{~min}$ at room temperature (RT). From round 2, competitor yeast tRNA ( 0.375 nmole) was also added to the reaction mixture. In rounds 3 and 4, SELEX was performed with equimolar ratio of RNA and toxin to increase the chances of RNA binding to the toxin. Later to improve the stringency of selection, RNA/toxin ratio was increased to $4 / 1$ and $8 / 1$ in rounds 5 and 7 , respectively (Table 1 ). The toxin-RNA mixture was then passed through a prewetted nitrocellulose filter followed by 5 times of washing with $200 \mu \mathrm{L}$ of selection buffer. The Stx1/Stx 2 bound RNA was eluted from the filter with $400 \mu \mathrm{L}$ TE Buffer (10 mM TRIS, $1 \mathrm{mM}$ EDTA; $\mathrm{pH} 8.0$ ) at $95^{\circ} \mathrm{C}$ for $5 \mathrm{~min}$, followed by ethanol precipitation.

The recovered RNA pool was reverse-transcribed into cDNA in a total volume of $20 \mu \mathrm{L}$ using MuLV Reverse Transcriptase (Applied Biosystems, CA) and amplified for 12 cycles of PCR followed by ethanol precipitation. Finally, the dsDNA was transcribed in vitro using T7 RNA polymerase and purified on $8 \%$ polyacrylamide/7 $\mathrm{M}$ urea gels as described above to synthesize the enriched RNA pool to be used for the next round of selection.

2.4. In Vitro Selection of Aptamers Using Microtiter Plate. SELEX was also performed using microtiter plate ( $\mathrm{p}$-SELEX) to select aptamers against Stx1 and Stx2. The 96-well plate (Evergreen Scientific, Los Angeles, CA) was coated with $20 \mu \mathrm{g} / \mathrm{mL}$ of Stxl-specific mouse monoclonal antibody (MAb) 4D3 or Stx2-specific mouse MAb 3D1 overnight followed by blocking with $1 \%$ BSA (Amgen, Thousand Oaks, CA) and binding with $20 \mu \mathrm{g} / \mathrm{mL}$ of Stx1 or Stx2 (28 pmoles), respectively, in the selection buffer (20 mM HEPES ( $\mathrm{pH} 7.4)$, $150 \mathrm{mM} \mathrm{NaCl}, 5 \mathrm{mM} \mathrm{MgCl} 2$, and $0.1 \%$ Tween 20) for $1 \mathrm{~h}$ at RT each. BSA was used instead of tRNA to reduce nonspecific binding of both toxins and RNA as described elsewhere for plate selection $[25,26]$. Prior to every round of selection, RNA was thermally equilibrated and refolded as described above and preabsorbed with 4D3/BSA- or 3D1/BSA-bound plate to minimize nonspecific binding of RNA to the plate. After preclearing, RNA was incubated with Stxl or Stx2 in $100 \mu \mathrm{L}$ of the selection buffer for $1 \mathrm{~h}$ at RT followed by washing 6 times with $200 \mu \mathrm{L}$ tween-selection buffer. Elution of RNA was performed by heating the plate at $95^{\circ} \mathrm{C}$ for $5 \mathrm{~min}$ and reverse transcription was directly done on the plate at $42^{\circ} \mathrm{C}$ in a total volume of $50 \mu \mathrm{L}$ with MuLV Reverse Transcriptase (Applied Biosystems) followed by amplification into DNA by PCR with Taq Polymerase (New England Biolabs). Finally, the DNA was transcribed in vitro using T7 RNA polymerase (Epicentre) and purified on $8 \%$ polyacrylamide/7 $\mathrm{M}$ urea gels to synthesize the enriched RNA pool to be used for the next round of selection.

2.5. Nitrocellulose Filter Binding Assay. Nitrocellulose filter binding assay was used to evaluate the RNA pool binding capability after every other round [27]. RNA pools after $0,1,3,5$, and 7 rounds of selection were radiolabelled 
TABLE 1: Concentrations of RNA aptamer pool and Stx1 or Stx2 for SELEX selection.

\begin{tabular}{lcccc}
\hline \multirow{2}{*}{ Selection round } & \multicolumn{2}{c}{ Membrane-SELEX } & \multicolumn{2}{c}{ Plate-SELEX } \\
& Input RNA (pmoles) & Input Stx1/Stx2 (pmoles) & Input RNA (pmoles) & Input Stx1/Stx2 (pmoles) \\
\hline 1 & 1600 & 400 & 400 & 28 \\
2 & 800 & 400 & 200 & 28 \\
3 & 200 & 200 & 200 & 28 \\
4 & 200 & 200 & 200 & 28 \\
5 & 200 & 50 & 200 & 28 \\
6 & 200 & 50 & 200 & 28 \\
7 & 200 & 25 & 200 & 28 \\
\hline
\end{tabular}

during transcription by incorporation of $[\alpha-32 \mathrm{P}]-\mathrm{ATP}$ and subsequently purified on $8 \%$ polyacrylamide $/ 7 \mathrm{M}$ urea gels. Thermally equilibrated $10 \mathrm{nM}$ radiolabelled RNA pools were incubated with $0.5 \mu \mathrm{M}$ of Stxl or Stx2 or BSA in selection buffer in the presence of $0.1 \mu \mathrm{g} / \mu \mathrm{L}$ yeast tRNA. The Stx1/Stx2RNA mixtures were then passed through a vacuum manifold containing nitrocellulose and nylon membranes (the nitrocellulose membrane captures RNA+ protein complexes, while the nylon membrane captures all free RNA that flows through the nitrocellulose membrane) and washed three times with selection buffer. Both nylon and nitrocellulose membranes were exposed to a phosphor screen for at least $4 \mathrm{~h}$ and the radioactivity was measured using phosphorimager (Molecular Dynamics Storm Phosphoimager 840, GE/Amersham). The fraction of RNA bound to the Stxl or Stx2 was calculated with the following formula: fraction bound $=\mathrm{cpm}$ on nitrocellulose $/(\mathrm{cpm}$ on nitrocellulose $+\mathrm{cpm}$ on nylon) $\times 100$.

2.6. Cloning and Sequencing. After 7 rounds of selection with no further enrichment observed, the dsDNA from round 5 of SELEX was amplified by PCR and cloned into pCR 2.1TOPO Vector cloning vector (Invitrogen, Grand Island, NY) and transformed into E. coli (Top 10 cells, Invitrogen). Fiftyone individual clones from membrane-SELEX (m-SELEX) and 45 clones from plate-SELEX (p-SELEX) were picked and sequenced using M13 forward primer. According to the alignments of individual sequences, membrane-SELEX aptamers were grouped into 5 groups and ELISA-SELEX aptamers were grouped into 4 groups. One representative sequence from each group was chosen for further analysis because of relative abundance within their group.

2.7. HeLa Cell Cytotoxicity Assay. An in vitro HeLa cell cytotoxicity, optimized to evaluate ability of RNA aptamers to neutralize cytotoxic effects of Stx2, was used. HeLa cells were cultured on 96-well plates at $1 \times 10^{4}$ cells/well in DMEM medium with $10 \%$ fetal bovine serum overnight at $37^{\circ} \mathrm{C}$ (complete DMEM medium). After reaching 60-70\% cell confluence, cells were washed 4 times with nuclease free phosphate-buffered saline (NF-PBS) (Ambion, TX, USA) before adding Stx2. Stx 2 at $0.5 \mathrm{ng} /$ well $(0.007$ pmole $)$ or $4 \mathrm{ng} /$ well $(0.056 \mathrm{pmole})$ was preincubated either with individual aptamers at $50 \mu \mathrm{g} /$ well $(1550$ pmole) or with Stx2neutralizing HuMAb $5 \mathrm{H} 8$ at $1.0 \mu \mathrm{g} /$ well $(6.66 \mathrm{pmole})$ at $37^{\circ} \mathrm{C}$ for $30 \mathrm{~min}$ before adding to the cells. All reagents were diluted in NF-PBS. Cells were then incubated with either Stx2 alone or Stx2 with RNA aptamers or Stx2 with $5 \mathrm{H} 8$ $\mathrm{HuMAb}$ at $37^{\circ} \mathrm{C}$ for $30 \mathrm{~min}$. The supernatants in the wells were collected and run on PAGE to determine degradation of RNA aptamers. The cells were again washed with NF-PBS 4 times and incubated in complete DMEM medium for $24 \mathrm{~h}$ at $37^{\circ} \mathrm{C}$. The percentage of cell survival in the presence or absence of aptamers and HuMAbs was assessed by crystal violet assay as described [28]. Briefly, cells were washed with PBS and fixed with $4 \%$ paraformaldehyde (PF). Crystal violet solution was added to the cells, and after intensive washing with water and drying, the cells were lysed with $100 \%$ ethanol. The optical density at $690 \mathrm{~nm}$ was measured in a microplate reader. The absorbance (OD) of each well was read at $590 \mathrm{~nm}$. The percentage of cell survival, which is a measurement of the toxin neutralization, was calculated by the following formula: $\left[\left(\mathrm{OD}_{\text {toxin in presence of } 5 \mathrm{H} 8 \text { or aptamer }}-\mathrm{OD}_{\text {toxin only }}\right) /\left(\mathrm{OD}_{\text {no toxin }}-\right.\right.$ $\left.\left(\mathrm{OD}_{\text {toxin only }}\right)\right] \times 100$.

2.8. Flow Cytometry Analysis. To determine whether Stx2specific aptamers inhibit binding of Stx2 to its receptor $\mathrm{Gb}_{3}$ on the cell surface, flow cytometry analysis was performed as described [29]. HeLa cell suspensions were produced by treating the cells with $0.05 \%$ trypsin- $53 \mathrm{mM}$ EDTA. Cells were then washed three times with cold NF-PBS by centrifugation at $300 \times \mathrm{g}$ at $4^{\circ} \mathrm{C}$ for $10 \mathrm{~min}$. AF488-labeled Stx2 (Stx2-AF) at $0.6 \mu \mathrm{g} / \mathrm{mL}(100 \mu \mathrm{L}, 0.8$ pmole)NF-PBS was preincubated at $37^{\circ} \mathrm{C}$ for $1 \mathrm{~h}$ with aptamers $(500 \mu \mathrm{g} / \mathrm{mL} \mathrm{NF}$ PBS, $100 \mu \mathrm{L}, 1550$ pmole), cooled to $4^{\circ} \mathrm{C}$, and then added to suspensions of $5 \times 10^{5}$ cells which were also precooled to $4^{\circ} \mathrm{C}$. After a $30 \mathrm{~min}$ incubation at $4^{\circ} \mathrm{C}$, the cells were washed twice in cold NF-PBS and resuspended in $4 \%$ PF for $15 \mathrm{~min}$ at $4^{\circ} \mathrm{C}$. The cells were washed and resuspended in PBS. The cell-associated fluorescence (20,000 cells per treatment) was collected by using BD Accuri C6 flow cytometer (BD Biosciences). Histogram analysis was performed by using $\mathrm{BD}$ Accuri C6 software.

\section{Results}

3.1. Selection of RNA Aptamers for Stx1 and Stx2. The filter binding assay was used to monitor the progress of selection after each SELEX cycle. Strong enrichment of N56 (56 random nucleotides) unmodified RNA aptamer pool for 


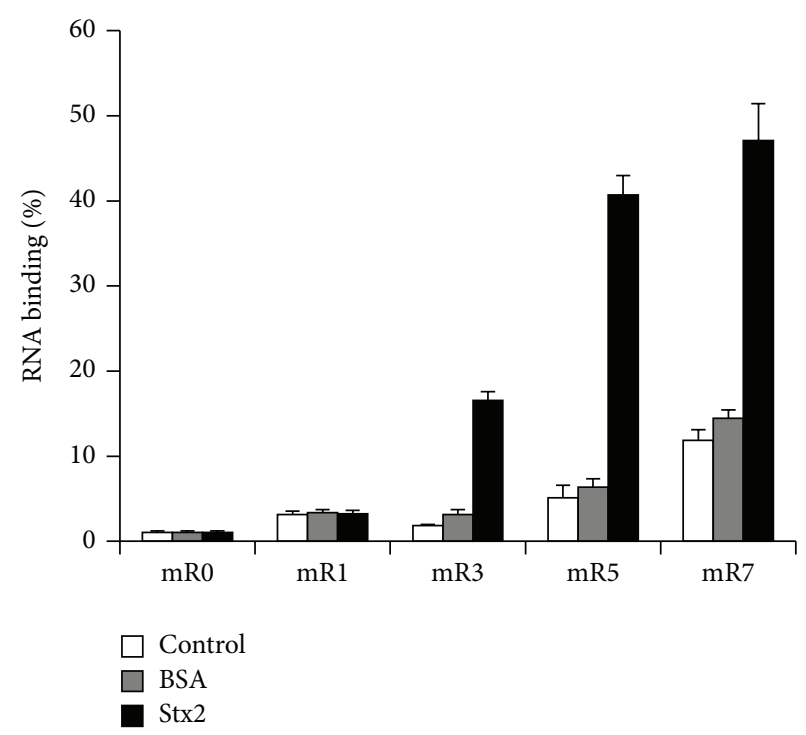

(a)

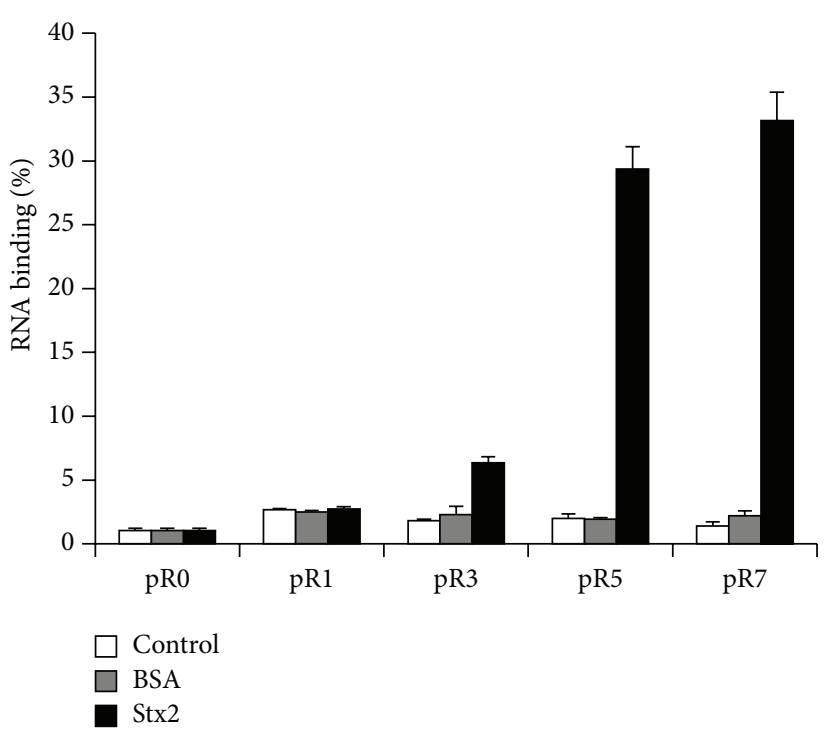

(b)

FIGURE 1: Enrichment of unmodified RNA aptamer pool of 56 random nucleotides for binding with Stx2 through successive selection rounds of SELEX. Binding activity of the RNA pool was analyzed by filter binding assay. Strong enrichment of aptamer pool for Stx2-binders occurred at 5 th round of selection by both m-SELEX (a) and p-SELEX (b) as $41 \%$ and $29 \%$ of the input RNA bound with Stx2, respectively, whereas binding to the membrane and unrelated protein BSA was $<5 \%$. The enrichment did not increase with additional rounds of selections. This experiment was repeated twice with similar results.

Stx2-binders occurred at 5 th round of selection by m-SELEX and p-SELEX as $41 \%$ and $29 \%$ of the input RNA bound with Stx2, respectively, whereas binding to the membrane and unrelated protein BSA was $<5 \%$ (Figure 1). The enrichment did not increase with additional rounds of selection by $\mathrm{m}$ SELEX as $47 \%$ of the input RNA bound with Stx 2 in 7 th round of selection, but nonspecific RNA binding to the membrane and BSA increased to $>12 \%$ (Figure 1(a)). Although 7 th round of selection by p-SELEX increased enrichment slightly to $33 \%$ with no increase in background binding (Figure 1(b)), the enrichment did not increase following additional rounds of selection by p-SELEX (data not shown). Therefore, highly enriched unmodified RNA aptamer pools of 5 th selection rounds by m-SELEX and p-SELEX were cloned and sequenced.

Although identical selection conditions were used to perform SELEX as mentioned above with two modified (nuclease resistant) libraries of 35 and 101 random nucleotides, we could not enrich libraries with Stx2-binders (data not shown). Similarly, none of the unmodified or modified libraries showed any enrichment for Stxl-binders even after 12-20 rounds of selection with each library (data not shown).

3.2. Analysis of the Selected Stx2 Aptamers. Highly enriched unmodified RNA aptamer pools for Stx2-binders were cloned, and $\sim 100$ clones from each pool were sequenced. The individual clones were classified into 5 groups from $\mathrm{m}$ SELEX and 5 groups from p-SELEX based on the alignments of individual aptamer sequences. One representative sequence from each group was chosen for further characterization because of their relative abundance within their group (Table 2). The sequences within each group were almost identical except groups $\mathrm{m}$-singles and $\mathrm{p}$-singles which contained sequences that occurred only once. Seventyeight percent of $\mathrm{m}$-SELEX sequences were grouped into groups $\mathrm{mA}$ and $\mathrm{mB}$ and $36 \%$ of p-SELEX sequences into groups $\mathrm{pA}$ and $\mathrm{pC}$. These groups contained an identical 19nucleotide (ATTCGATCAGGCAGTACGT) region (Table 2). Furthermore, sequences of groups $\mathrm{mA}$ and $\mathrm{mB}$ were identical to sequences of groups $\mathrm{pC}$ and $\mathrm{pA}$, respectively. However, the other 4 groups $(\mathrm{mC}, \mathrm{mD}, \mathrm{pB}$, and $\mathrm{pD}$ ) did not have any similarities between them. Filter binding assay was performed to confirm the binding activity of these selected individual aptamers with Stx2 (Figure 2). Except for the group mC (mC_Apt41), all other groups showed strong specific binding with Stx2. Nonetheless, mC_Apt41 also bound Stx2. None of the aptamers from any group bound Stxl (results not shown).

3.2.1. Flow Cytometry Analysis. In absence of any aptamer, Stx2-AF $(0.6 \mu \mathrm{g} / \mathrm{mL}, 8 \mathrm{nM})$ labeled $\sim 78 \%$ of the HeLa cells (Figure 3). Control aptamer did not block binding of Stx2 with HeLa cells as $76 \%$ cells were labeled by Stx2-AF. Most of the Stx2-specific aptamers (mA_Apt1, mB_Apt23, mC_Apt41, mD_Apt46, pA_Apt1, and pCApt22) inhibited Stx2 binding weakly as approximately $50 \%$ of HeLa cells were labeled in the presence of these aptamers (Figure 3). Similar to the unrelated control aptamer, the remaining 2 Stx2-binding aptamers (pB_Apt14 and pD_Apt25) did not inhibit Stx2 binding (Figure 3). 
TABLE 2: Sequences of RNA aptamers selected following membrane- and plate-SELEX.

\begin{tabular}{|c|c|c|}
\hline Group & $n^{1}$ & Sequence $^{2}$ \\
\hline $\mathrm{mA}$ & 43 & ATTAGCTATCTTCCACGATTCGATCAGGCAGTACGTCGT ${ }^{3,4}$ \\
\hline $\mathrm{mB}$ & 35 & ACAGTTATCCGACTGCTATTCGATCAGGCAGTACGTAGC \\
\hline $\mathrm{mC}$ & 6 & CAGGCTGTTCTGACGCATAAGGAATGCGCTGTTGCAGAG \\
\hline $\mathrm{mD}$ & 4 & TTGGTCCTGCTTTGGATAGTCGCGAAAGGGGTGCCACTG \\
\hline m-Singles & 8 & Orphan sequences $^{6}$ \\
\hline $\mathrm{pA}$ & 29 & ACAGTTATCCGACTGCTATTCGATCAGGCAGTACGTAGC 3,5 \\
\hline $\mathrm{pB}$ & 18 & ACCGAGCGGTTTTACGTCTCAAGTAGTATCCCGTTTTGC \\
\hline $\mathrm{pC}$ & 7 & ATTAGCTATCTTCCACGATTCGATCAGGCAGTACGTCGT \\
\hline $\mathrm{pD}$ & 4 & TTGCCATCCTGTACTATGCTCTATCGGGCGGTTTAGTGATCCTTCGTCCAACTATC \\
\hline p-Singles & 42 & Orphan sequences $^{5}$ \\
\hline
\end{tabular}

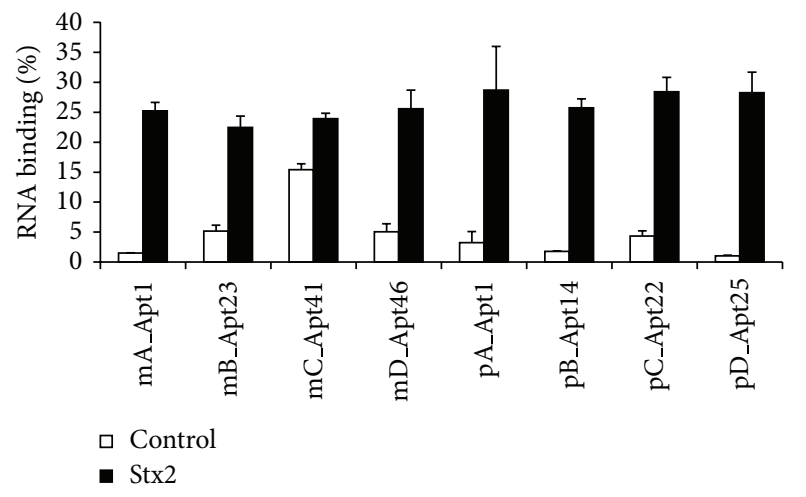

FIgURE 2: Binding of individual aptamers with Stx2. The binding activity of the individual aptamers with Stx2 was analyzed by filter binding assay. All aptamer sequences showed strong binding with Stx2 except mC_Apt41 which showed moderate binding as it also bound nonspecifically to the membrane more than the other aptamers. This experiment was repeated twice with similar results.

3.2.2. Neutralization of Stx2-Mediated HeLa Cell Cytotoxicity by Aptamers. A limited neutralization of Stx2-mediated cytotoxicity and death of HeLa cells was observed with aptamers mA_Apt1 ( $\sim 40 \%$ cell survival), mB_Apt23 ( 20\% cell survival), and pC_Apt22 ( $\leq 60 \%$ cell survival) (Figure 4$)$. Aptamer mC_Apt41 neutralized 0.007 pmole of Stx2 $(\leq 60 \%$ cell survival) but not 0.056 pmole of Stx2 (Figure 4). None of the other aptamers neutralized the cytotoxic effects of Stx2 (Figure 4). RNA aptamers did not degrade in the HeLa cell assay as RNA band of HeLa cell-incubated aptamer was of similar intensity in PAGE analysis as that of the unincubated aptamer (not shown).

\section{Discussion}

The goal of the present study was to identify aptamers that can bind and inactivate Stx1 and Stx2. The well known in vitro SELEX procedure $[17,18]$ was used to derive RNA aptamers that specifically bind to Stxl and Stx2. Aptamer libraries without any modifications were used initially to demonstrate proof-in-principle that SELEX can be used to identify aptamers for Stxl and Stx2. Generally, the aptamer pools with short randomized regions (15 nucleotides) are sufficient for a successful aptamer selection [30]. However, longer randomized regions give the pools a greater structural complexity $[31,32]$ and an increased possibility for selection of high-affinity aptamers [33]. Thus, we initially performed SELEX using a RNA pool containing $5 \times 10^{14}$ unique sequences with a central stretch of 56 random nucleotides (N56) and identified aptamers that bound Stx2. However, despite using the same N56 pool and other pools with random nucleotide lengths (N35 and N101) and the same selection conditions as used for Stx2, we could not identify aptamers that bound Stxl. Although reasons for not identifying Stxlbinding aptamers are unclear, it can be assumed that Stxl may not be a "good" target as evidenced by other studies that not every target is suitable for aptamer selection $[32,34]$.

Nucleic acid aptamers with binding affinities comparable to those of antibodies have been utilized for flexible applications ranging from diagnostic to therapeutic assay formats. To our knowledge this is the first study that attempted to discover aptamers against Stx2 and identified 6 unique unmodified RNA aptamer groups with Stx2-binding abilities. Although the Stx2-binding aptamers were discovered using N56 aptamer library, almost all aptamers had 39 random nucleotides except the group pD aptamers which had 56 random nucleotides. This is a common occurrence $[35,36]$ which might be because of the accumulation of either nearfull length or nonfull length products in the pool during synthesis or primers recognizing the sequence of nucleotides similar to constant region in the randomized region [37].

All aptamers that bound Stx 2 in the filter-binding assay also inhibited Stx2 binding partially with the HeLa cells except the aptamers of groups $\mathrm{pB}$ and $\mathrm{pD}$ which did not inhibit Stx2 binding. As antibodies that bind Stx2 B subunit but not A subunit are known to inhibit binding of the toxin with its cell surface [29], aptamers of groups $\mathrm{mA}$, $\mathrm{mB}, \mathrm{mC}, \mathrm{mD}, \mathrm{pA}$, and $\mathrm{pC}$ that inhibited Stx 2 binding may bind Stx2 B subunit. The Stx2-inhibiting aptamers seem to 

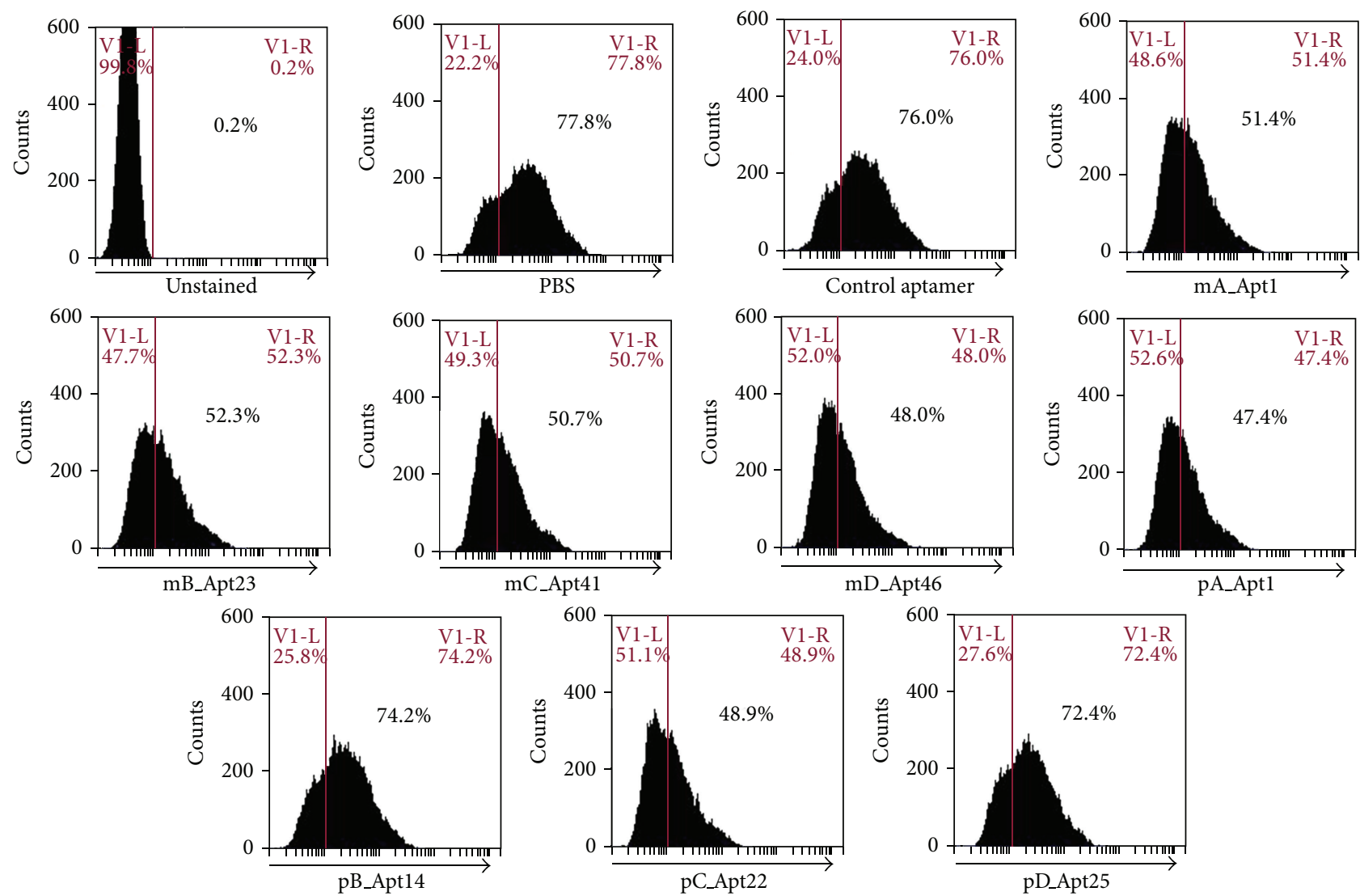

Figure 3: Flow cytometry analysis of HeLa cells treated with Stx2 and aptamers. Flow cytometry analysis showed that, in absence of any aptamer, Stx2-AF labeled $\sim 78 \%$ of the HeLa cells, and in presence of an unrelated control aptamer, Stx2-AF labeled 76\% cells. Most of the Stx2-specific aptamers (mA_Apt1, mB_Apt23, mC_Apt41, mD_Apt46, pA_Apt1, and pCApt22) inhibited Stx2 binding weakly as approximately $50 \%$ of HeLa cells were labeled in the presence of these aptamers. Similar to the unrelated control aptamer, the remaining 2 Stx2-binding aptamers (pB_Apt14 and pD_Apt25) did not inhibit Stx2 binding. This experiment was repeated twice with similar results.

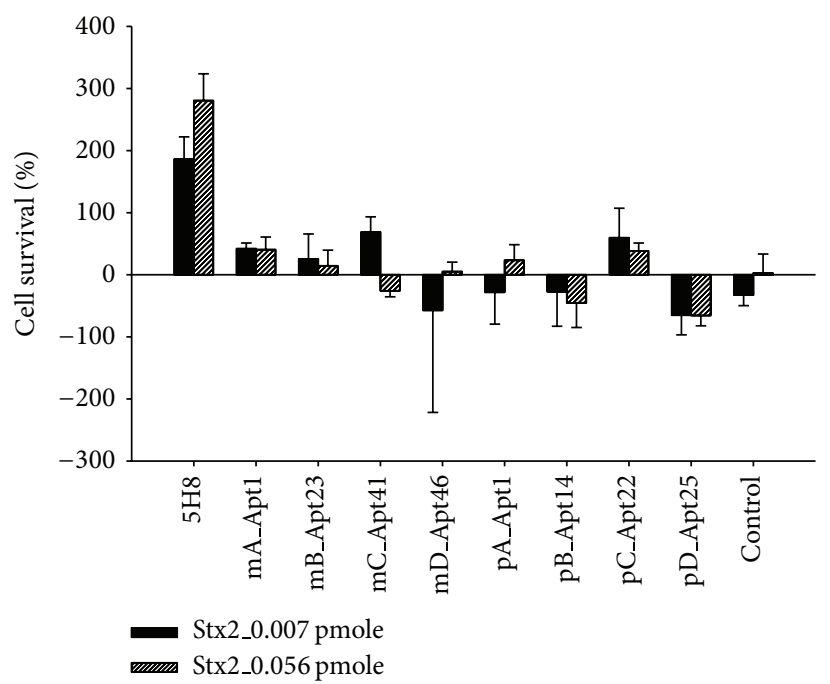

Figure 4: Neutralization of Stx2 activity by aptamers (1550 pmoles) in HeLa cell cytotoxicity Assay. Stx2-specific HuMAb 5H8 (6.66 pmole) strongly neutralized Stx 2 activity at both toxin concentrations ( 0.007 pmole and 0.056 pmole). A limited neutralization of Stx 2 activity was observed with aptamers mA_Apt1 ( $\sim 40 \%$ cell survival), mB_Apt23 ( 20\% cell survival), and pC_Apt22 ( $\leq 60 \%$ cell survival). Aptamer mC_Apt41 neutralized 0.007 pmole of Stx2 $(\leq 60 \%$ cell survival) but not 0.056 pmole of Stx2. None of the other aptamers neutralized the cytotoxic effects of Stx2. This experiment was repeated twice with similar results. 
be of low affinity as very high concentrations (1550 pmole) of the aptamers relative to Stx 2 concentrations ( 0.8 pmole) could not inhibit toxin binding completely. The affinity of aptamer was not increased as unmodified aptamers are nuclease sensitive which makes them unsuitable for therapy. These aptamers lost their ability to bind with Stx2 following modification (by incorporating Flourine at the $2^{\prime}$ position in pyrimidine bases) to gain nuclease resistant.

Very high concentrations of aptamers (1550 pmole) neutralized two different concentrations of Stx2 (0.007 pmole and 0.056 pmole) only marginally in HeLa cell assay. In contrast, the HuMAb $5 \mathrm{H} 8$ at 6.66 pmole (232 times lower than the aptamer concentrations) completely neutralized Stx2 at the two toxin concentrations. As very high concentrations of aptamers did not neutralize toxin's activity completely, dose response studies with aptamers were not performed. The insignificant neutralization of the toxin was not due to degradation of the aptamers as HeLa cell assay was performed in nuclease free conditions, and RNA aptamers did not degrade following incubation with HeLa cells.

Although we standardized SELEX to select Stx2-specific unmodified aptamers, our repeated attempts with modified libraries generated using $2^{\prime}$-Fluorine-CTP $\left(2^{\prime}\right.$-F-dCTP $)$ and $2^{\prime}$-Fluorine-UTP (2'-F-dUTP) to identify nuclease resistant RNA aptamers against Stxl or Stx 2 were unsuccessful. As the $2^{\prime}$-fluoro modifications on the ribose ring influence the tertiary structure of an oligonucleotide, it may be expected that modified aptamers form completely unrelated structures compared to unmodified aptamers [23]. Moreover, we could not enrich the libraries with Stx2- or Stx1-binders as background binding was always as much as binding with Stx2 or Stxl even after 12 rounds and, in a couple of instances, 20 rounds, of selection which might be because of increased hydrophobicity due to replacement of $\mathrm{OH}$ with fluorine in the RNA. This shows that SELEX technology is hard to adapt to select aptamers against some targets, such as Stx [34].

\section{Conclusions}

SELEX procedures, $\mathrm{p}$-SELEX and $\mathrm{m}$-SELEX, yielded unmodified aptamers that bound Stx2 but not Stxl. Each procedure generated 2 groups of Stx2-binding aptamer sequences that were unique to each SELEX procedure and another 2 groups of Stx2-binding aptamer sequences that were shared by the 2 SELEX procedures. These aptamers may be useful to develop Stx2-specific diagnostic assays in the future. Several attempts with modified RNA aptamer libraries to generate nuclease resistant aptamers against Shiga toxins were unsuccessful.

\section{Conflict of Interests}

The authors declare that they do not have any conflict of interests with the content of the paper.

\section{Acknowledgments}

The authors thank Drs. Matthew Levy and Sonald Duclaire, Department of Biochemistry, Albert Einstein College of
Medicine, for training them with the filter binding assay and their thoughtful discussions on selection of aptamers. This study was supported by Federal Funds from the National Institute of Allergy and Infectious Diseases, National Institutes of Health, under Award nos. AI083369 and AI082079. A. Sheoran was also supported by the Usen Family Career Development Award. The content is solely the responsibility of the authors and does not necessarily represent the official views of the National Institute of Allergy and Infectious Diseases or the National Institutes of Health.

\section{References}

[1] P. Boerlin, S. A. McEwen, F. Boerlin-Petzold, J. B. Wilson, R. P. Johnson, and C. L. Gyles, "Associations between virulence factors of Shiga toxin-producing Escherichia coli and disease in humans," Journal of Clinical Microbiology, vol. 37, no. 3, pp. 497503, 1999.

[2] P. M. Griffin and R. V. Tauxe, "The epidemiology of infections caused by Escherichia coli O157:H7, other enterohemorrhagic $E$. coli, and the associated hemolytic uremic syndrome," Epidemiologic Reviews, vol. 13, no. 1, pp. 60-98, 1991.

[3] D. V. Milford, C. M. Taylor, B. Guttridge, S. M. Hall, B. Rowe, and H. Kleanthous, "Haemolytic uraemic syndromes in the British Isles 1985-8: association with verocytoxoin producing Escherichia coli. Part 1: clinical and epidemiological aspects," Archives of Disease in Childhood, vol. 65, no. 7, pp. 716-721, 1990.

[4] S. M. Ostroff, P. I. Tarr, M. A. Neill, J. H. Lewis, N. Hargret-Bean, and J. M. Kobayashi, "Toxin genotypes and plasmid profiles as determinants of systemic sequelae in Escherichia coli O157:H7 infections," The Journal of Infectious Diseases, vol. 160, no. 6, pp. 994-998, 1989.

[5] A. W. Friedrich, M. Bielaszewska, W.-L. Zhang et al., "Escherichia coli harboring Shiga toxin 2 gene variants: frequency and association with clinical symptoms," The Journal of Infectious Diseases, vol. 185, no. 1, pp. 74-84, 2002.

[6] H. Russmann, H. Schmidt, J. Heesemann, A. Caprioli, and H. Karch, "Variants of Shiga-like toxin II constitute a major toxin component in Escherichia coli O157 strains from patients with haemolytic uraemic syndrome," Journal of Medical Microbiology, vol. 40, no. 5, pp. 338-343, 1994.

[7] S. Tzipori, A. Sheoran, D. Akiyoshi, A. Donohue-Rolfe, and H. Trachtman, "Antibody therapy in the management of Shiga toxin-induced hemolytic uremic syndrome," Clinical Microbiology Reviews, vol. 17, no. 4, pp. 926-941, 2004.

[8] M. E. Fraser, M. Fujinaga, M. M. Cherney et al., "Structure of Shiga toxin type 2 (Stx2) from Escherichia coli O157:H7," The Journal of Biological Chemistry, vol. 279, pp. 27511-27517, 2004.

[9] H. Ling, A. Boodhoo, B. Hazes et al., "Structure of the Shiga-like toxin I B-pentamer complexed with an analogue of its receptor Gb3," Biochemistry, vol. 37, no. 7, pp. 1777-1788, 1998.

[10] H. Shimizu, R. A. Field, S. W. Homans, and A. DonohueRolfe, "Solution structure of the complex between the B-subunit homopentamer of verotoxin VT-1 from Escherichia coli and the trisaccharide moiety of globotriaosylceramide," Biochemistry, vol. 37, no. 31, pp. 11078-11082, 1998.

[11] C. A. Lingwood, H. Law, S. Richardson et al., "Glycolipid binding of purified and recombinant Escherichia coli produced verotoxin in vitro," The Journal of Biological Chemistry, vol. 262, no. 18 , pp. $8834-8839,1987$. 
[12] T. Waddell, S. Head, M. Petric, A. Cohen, and C. Lingwood, "Globotriosyl ceramide is specifically recognized by the Escherichia coli verocytotoxin 2," Biochemical and Biophysical Research Communications, vol. 152, no. 2, pp. 674-679, 1988.

[13] C. A. Lingwood, "Role of verotoxin receptors in pathogenesis," Trends in Microbiology, vol. 4, no. 4, pp. 147-153, 1996.

[14] Y. Endo, K. Tsurugi, T. Yutsudo, Y. Takeda, T. Ogasawara, and K. Igarashi, "Site of action of a Vero toxin (VT2) from Escherichia coli $\mathrm{O} 157: \mathrm{H7}$ and of Shiga toxin on eukaryotic ribosomes. RNA N-glycosidase activity of the toxins," European Journal of Biochemistry, vol. 171, no. 1-2, pp. 45-50, 1988.

[15] S. K. Saxena, A. D. O’Brien, and E. J. Ackerman, "Shiga toxin, Shiga-like toxin II variant, and ricin are all single-site RNA Nglycosidases of $28 \mathrm{~S}$ RNA when microinjected into Xenopus oocytes," The Journal of Biological Chemistry, vol. 264, no. 1, pp. 596-601, 1989.

[16] L. H. Lauridsen and R. N. Veedu, "Nucleic acid aptamers against biotoxins: a new paradigm toward the treatment and diagnostic approach," Nucleic Acid Therapeutics, vol. 22, no. 6, pp. 371-379, 2012.

[17] C. Tuerk and L. Gold, "Systemic evolution of ligands by exponential enrichment: RNA ligands to bacteriophage T4 DNA polymerase," Science, vol. 249, no. 4968, pp. 505-510, 1990.

[18] A. D. Ellington and J. W. Szostak, "In vitro selection of RNA molecules that bind specific ligands," Nature, vol. 346 , no. 6287 , pp. 818-822, 1990.

[19] M. Famulok, J. S. Hartig, and G. Mayer, "Functional aptamers and aptazymes in biotechnology, diagnostics, and therapy," Chemical Reviews, vol. 107, no. 9, pp. 3715-3743, 2007.

[20] S. M. Nimjee, C. P. Rusconi, and B. A. Sullenger, "Aptamers: an emerging class of therapeutics," Annual Review of Medicine, vol. 56, pp. 555-583, 2005.

[21] M. Fan, S. R. McBurnett, C. J. Andrews, A. M. Allman, J. G. Bruno, and J. L. Kiel, "Aptamer selection express: a novel method for rapid single-step selection and sensing of aptamers," Journal of Biomolecular Techniques, vol. 19, no. 5, pp. 311-319, 2008.

[22] A. Donohue-Rolfe, D. W. K. Acheson, A. V. Kane, and G. T. Keusch, "Purification of Shiga toxins and Shiga-like toxin I and II by receptor analog affinity chromatography with immobilized P1 glycoprotein and production of cross-reactive monoclonal antibodies," Infection and Immunity, vol. 57, no. 12, pp. 38883893, 1989.

[23] J. Ruckman, L. S. Green, J. Beeson et al., "2'-fluoropyrimidine RNA-based aptamers to the 165-amino acid form of vascular endothelial growth factor (VEGF165): inhibition of receptor binding and VEGF-induced vascular permeability through interactions requiring the exon 7-encoded domain," The Journal of Biological Chemistry, vol. 273, no. 32, pp. 20556-20567, 1998.

[24] R. Padilla and R. Sousa, "A Y639F/H784A T7 RNA polymerase double mutant displays superior properties for synthesizing RNAs with non-canonical NTPs," Nucleic Acids Research, vol. 30, no. 24, article e138, 2002.

[25] L. V. Gening, S. A. Klincheva, A. Reshetnjak, A. P. Grollman, and H. Miller, "RNA aptamers selected against DNA polymerase $\beta$ inhibit the polymerase activities of DNA polymerases $\beta$ and $\kappa$," Nucleic Acids Research, vol. 34, no. 9, pp. 2579-2586, 2006.

[26] A. Berezhnoy, C. A. Stewart, J. O. Mcnamara II et al., "Isolation and optimization of murine IL-10 receptor blocking oligonucleotide aptamers using high-throughput sequencing," Molecular Therapy, vol. 20, no. 6, pp. 1242-1250, 2012.
[27] S. D. Jhaveri and A. D. Ellington, "In vitro selection of RNA aptamers to a protein target by filter immobilization," in Current Protocols in Molecular Biology, chapter 9, unit 9.3, 2001.

[28] A. S. Sheoran, S. Chapman-Bonofiglio, B. R. Harvey et al., "Human antibody against Shiga toxin 2 administered to piglets after the onset of diarrhea due to Escherichia coli O157:H7 prevents fatal systemic complications," Infection and Immunity, vol. 73, no. 8, pp. 4607-4613, 2005.

[29] G. Krautz-Peterson, S. Chapman-Bonofiglio, K. Boisvert et al., "Intracellular neutralization of Shiga toxin 2 by an A subunitspecific human monoclonal antibody," Infection and Immunity, vol. 76, no. 5, pp. 1931-1939, 2008.

[30] L. C. Bock, L. C. Griffin, J. A. Latham, E. H. Vermaas, and J. J. Toole, "Selection of single-stranded DNA molecules that bind and inhibit human thrombin," Nature, vol. 355, no. 6360, pp. 564-566, 1992.

[31] K. A. Marshall and A. D. Ellington, "In vitro selection of RNA aptamers," Methods in Enzymology, vol. 318, pp. 193-214, 2000.

[32] R. Stoltenburg, C. Reinemann, and B. Strehlitz, "SELEX-a (r)evolutionary method to generate high-affinity nucleic acid ligands," Biomolecular Engineering, vol. 24, no. 4, pp. 381-403, 2007.

[33] S. Klussmann, The Aptamer Handbook: Functional Oligonucleotides and Their Applications, Wiley-VCH, 2006.

[34] B. Hall, S. Arshad, K. Seo et al., "In vitro selection of RNA aptamers to a protein target by filter immobilization," in Current Protocols in Molecular Biology, chapter 9, unit 9.3, pp. 1-27, 2010.

[35] C. Mannironi, A. di Nardo, P. Fruscoloni, and G. P. TocchiniValentini, "In vitro selection of dopamine RNA ligands," Biochemistry, vol. 36, no. 32, pp. 9726-9734, 1997.

[36] A. Geiger, P. Burgstaller, H. von der Eltz, A. Roeder, and M. Famulok, "RNA aptamers that bind L-arginine with submicromolar dissociation constants and high enantioselectivity," Nucleic Acids Research, vol. 24, no. 6, pp. 1029-1036, 1996.

[37] B. Hall, J. M. Micheletti, P. Satya, K. Ogle, J. Pollard, and A. D. Ellington, "Design, synthesis, and amplification of DNA pools for in vitro selection," Current Protocols in Nucleic Acid Chemistry, chapter 9, unit 9.2, 2009. 

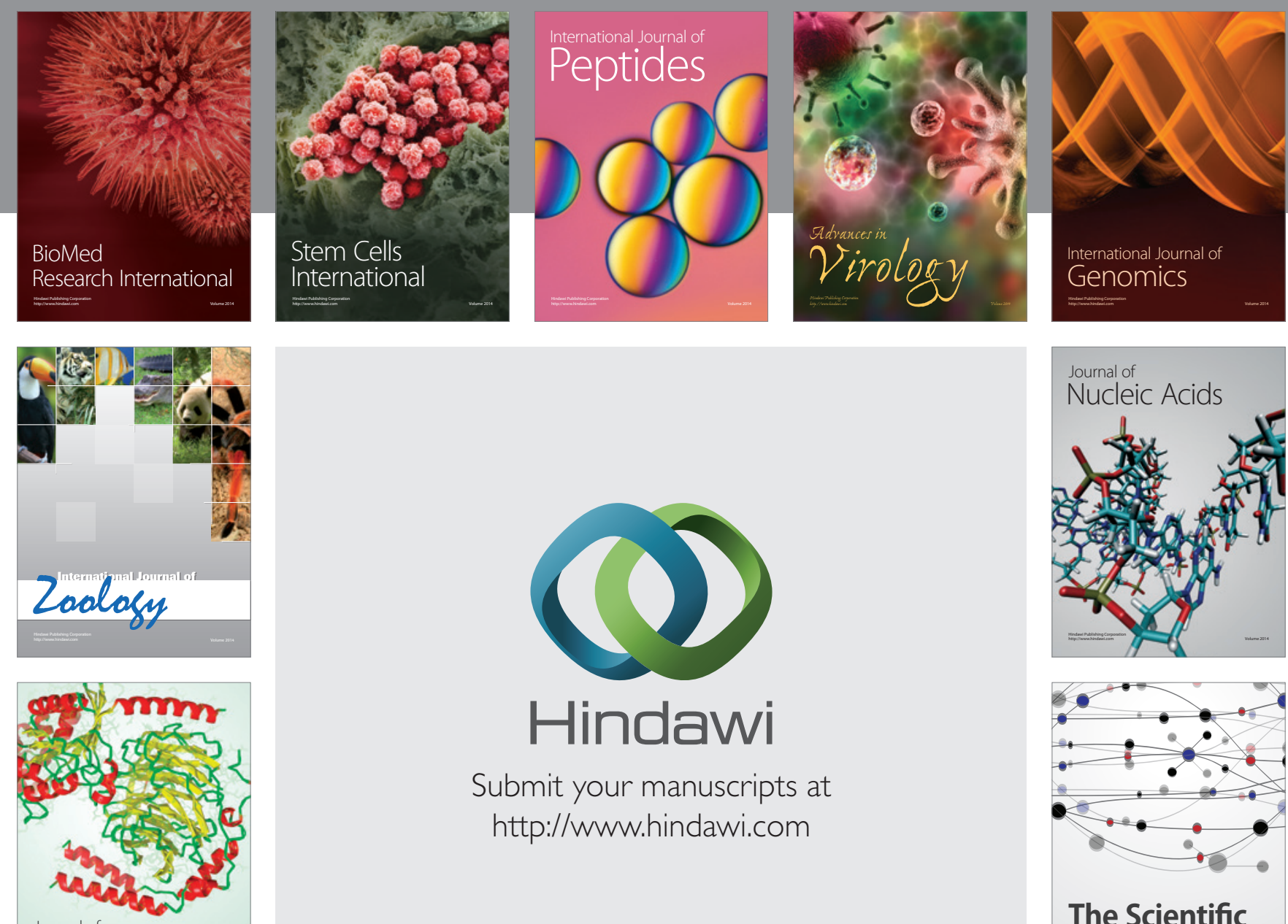

Submit your manuscripts at

http://www.hindawi.com

Journal of
Signal Transduction
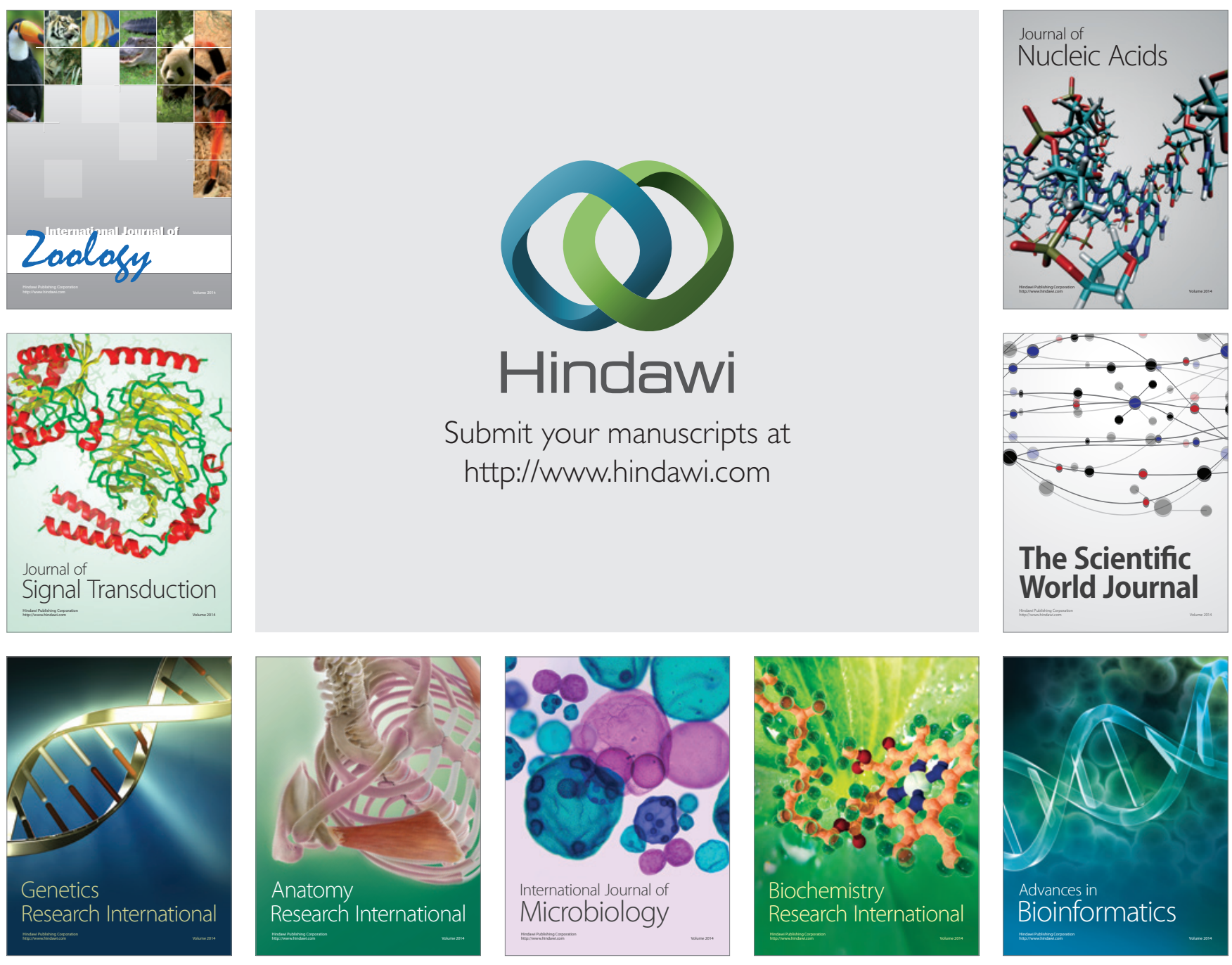

The Scientific World Journal
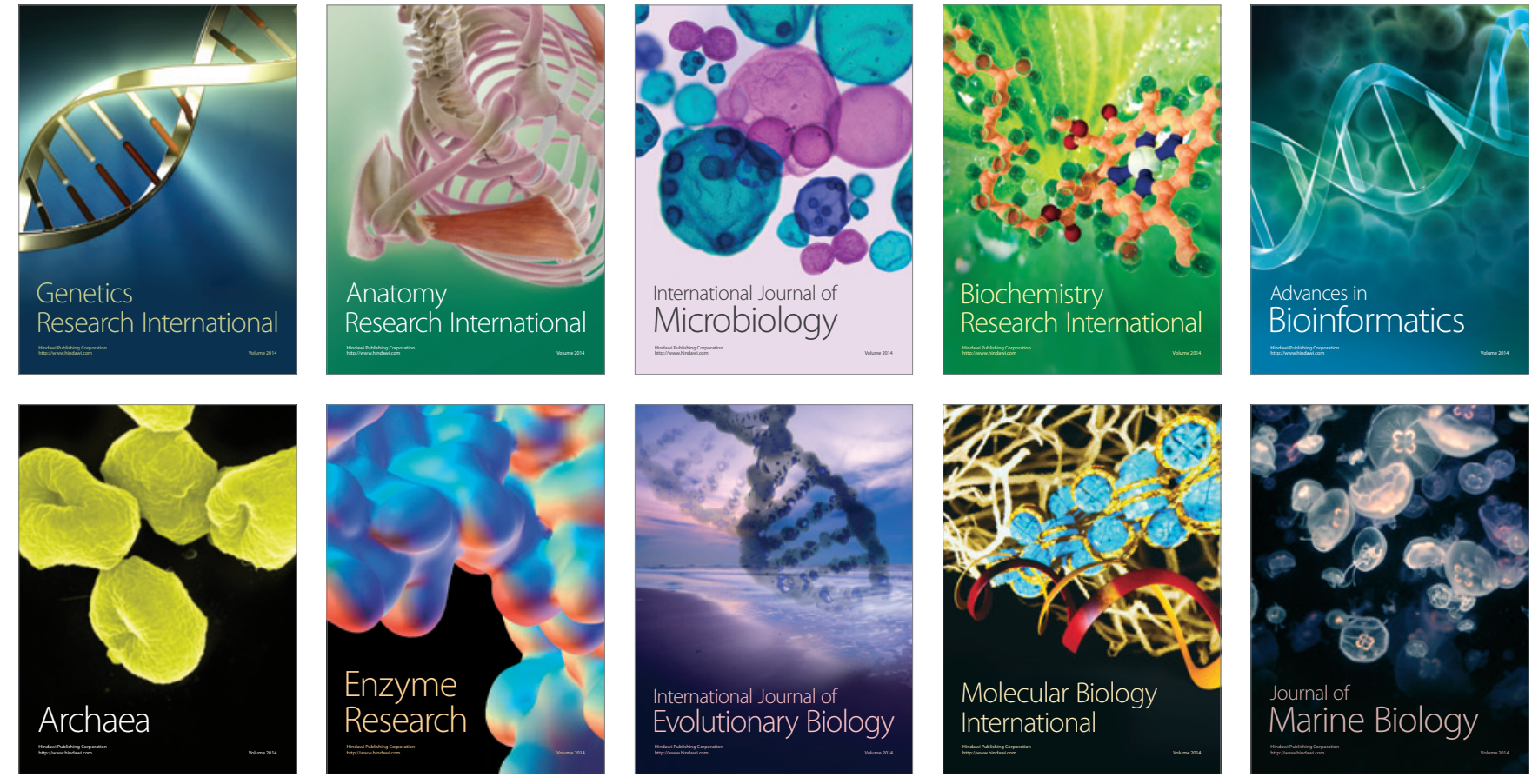